\title{
ADVANCED LUMPED PARAMETER MODEL FOR SWITCHED RELUCTANCE MOTORS WITH HIGH PERFORMANCE COOLING
}

\author{
J. Nonneman ${ }^{1,3 *}$, N. Clarie ${ }^{2,3}$, I. T'Jollyn ${ }^{1,3}$, S. Schlimpert ${ }^{3}$, P. Sergeant ${ }^{2,3}$, M. De Paepe ${ }^{1,3}$ \\ ${ }^{1}$ Department of Flow, Heat and Combustion Mechanics, Ghent University, Sint-Pietersnieuwstraat 41, 9000 Ghent, Belgium \\ ${ }^{2}$ Department of Electrical Energy, Systems and Automation, Ghent University, Sint-Pietersnieuwstraat 41, 9000 Ghent, Belgium \\ ${ }^{3}$ Flanders Make vzw, Celestijnenlaan 300 - bus 4027, 3000, Leuven, Belgium
}

\begin{abstract}
In this paper an advanced thermal lumped parameter model for a switched reluctance electric motor (SRM) is constructed, based on a 2D thermal finite element simulation of a radial cross section of the motor. When applying and combining advanced cooling methods such as direct coil cooling, end winding cooling (radial stretched) and spray cooling on an SRM, the conventional lumped parameter models can no longer be used due to the 3D and complex temperature gradients in the motor. In standard LP models, mostly one simple cooling method is implemented by which the thermal gradients are also quite simple (1D or 2D). When combining different cooling methods, the gradients become highly 3D and these LPM are no longer valid. To improve the accuracy of this problem, a fully 3D thermal finite element simulation could be performed, but this would unnecessarily increase effort, complexity and computational time. To avoid this an advanced lumped parameter model is constructed in this paper, such that the high thermal gradients are modeled in more detail. The results from one 2D finite element simulation of a radial cross section of half of a stator tooth are reduced to a simpler lumped parameter model with more nodes in the most crucial parts, i.e., where the highest thermal gradients are expected. The 2D thermal model is then expanded to a 3D lumped parameter model, including the gradients in axial direction. Using this model, various cooling configurations and geometry parameters can be varied easily such that the design of an SRM with advanced cooling can be optimized efficiently.
\end{abstract}

KEY WORDS: Numerical simulation, Electronic equipment cooling, Lumped parameter model, Switched reluctance motor, 2D thermal finite element, High performance motor cooling

\section{INTRODUCTION}

With the recent rise of electrification in the automotive industry, the components used in these electrified drivetrains become more and more important. The most popular motor used for these electric vehicles is the Interior Permanent Magnet Synchronous Motor (IPMSM), but this motor uses rare-earth magnets. The Switched Reluctance Motor (SRM) would be a promising and cheaper alternative, because of its simple and robust design and due to the fact that it does not use expensive rare-earth magnets. The main drawbacks of the SRM are currently the high level of noise and difficulties with the practical implementations, but step by step these drawbacks are eliminated [1]. The high power density of these motors decreases the weight and its cost, however, results in a lot of heat which is dissipated in a small volume. Due to the working principle of the SRM, most of the heat will be dissipated in the coils and together with the very low thermal conductivity and volume of this component, this will result in very high temperatures in the coils. These temperatures should not exceed the maximum coil temperature depending on the materials used in the coil (insulation class), otherwise the coils can get damaged. The stator and rotor laminations will also heat up and can get damaged due to overheating. [2] 
To limit the temperature of the laminations and coils, several cooling methods can be applied. The most convenient cooling method used for electric machines is water jacket cooling, but this cooling method is located relatively far away from the coils where most of the heat is generated in this case [3]. Different attempts have already been studied to increase the power density by using advanced cooling methods for the SRM [2]. By analysing the different proposals, two main principles can be observed. Some of the authors used a technique to get the heat out of the coils by inserting heat paths between the adjacent coils, which transfer the heat via a highly conductive path to the stator laminations and afterwards to the water jacket [3]. Another possibility to attain an efficient cooling path, is to adjust the coil design such that the radial thermal conductivity is increases which can be achieved by, e.g., the use of edgewise windings [2] or rectangular wires [4]. Furthermore, a promising approach is to adjust the SRM cooling design, such that the distance between the liquid cooling and the coil is decreased. Several possibilities have been studied in the literature, i.e. direct coil cooling (dry or wet) [4] [5] [6] [7] [8] [9], spray cooling [10], immersion spray cooling [11] and end winding cooling [2]. A combination of the previously mentioned cooling approaches can be achieved by stretching the end windings (pull apart the wires in layers) which eliminates the bad radial thermal conductivity of the coil. Thus, the high axial conductivity of the coil is used to transfer the heat out of the coil. The end winding layers can then be cooled very locally by a dielectric fluid [12].

Before implementing certain cooling methods in the motor design, a comparison between the performance of the different methods is very important to make. However, out of the existing literature it is very difficult to compare the performance of the different possible methods for a SRM, because the design of the simulated or experimented SRM's are different and the boundary conditions vary highly in the aforementioned literature. Therefore it is important to make a model based comparison between the different methods, starting from the same geometry and boundary conditions. To make this comparison, a 3D lumped parameter model is preferred instead of a fully 3D FE simulation because the latter increases the complexity and computational time of the simulations. In the framework of the ICON Hipercool project, a generic model was constructed to simulate different geometries of SR motors and different designs of cooling methods. Based on the first simulations with this model, several conclusions can be made about water jacket, direct coil and stretched end winding cooling, and the combination of these techniques.

In this paper, firstly the motor geometry and principles will be elaborated, together with the applied cooling geometries. Afterwards the constructed lumped parameter model will be described and simulations with this model will be done for the cooling methods, followed by the general conclusions for these methods.

\section{MOTOR LAYOUT AND APPLIED COOLING METHODS}

A sectional view of a typical SRM is shown in Fig. 1. The exact electromagnetic working principle and design of this motor are out of scope of this paper, but it is important for the further understanding that some aspects are explained. A SRM works with only one magnetic field which is generated by the stator coils and the torque is the effect of the tendency to go to a minimum state of reluctance [1]. The resistive heat losses in the coil dominate the other losses, followed by the iron losses in stator and rotor laminations. Due to the high heat generation per volume of the coils and the low radial thermal conductivity (in the order of $1 \mathrm{~W} / \mathrm{mK}$ ), caused by the insulation and filling material between the wires, the temperatures in the coil will get the highest [13].

To limit the copper losses for a certain power level, the amount of copper in the stator slot should be as high as possible, i.e., the filling factor should be increased, e.g., with very precisely wound preformed coils, or by trying to fill the complete slot with wires [14]. A high filling factor is also beneficial for the radial thermal conductivity of the coil [15]. Unfortunately, these two possibilities are in contrast to each other because of a practical issue. The shape of the stator slot does not allow to insert two adjacent preformed coils in the slot, which would completely fill the slot. When using preformed coils it is limited to an almost rectangular shape as can be seen on Fig. 1. Thus, using preformed coils with a high fill factor results in a triangular open space formed by the two coils. The size of this triangular space is dependent on the amount of stator poles, i.e., more stator poles will result in a more rectangular stator slot with a smaller triangular space. The second option is 
to push two non-impregnated coils in the slot and try to completely fill the slot, but this results in low filling factors.
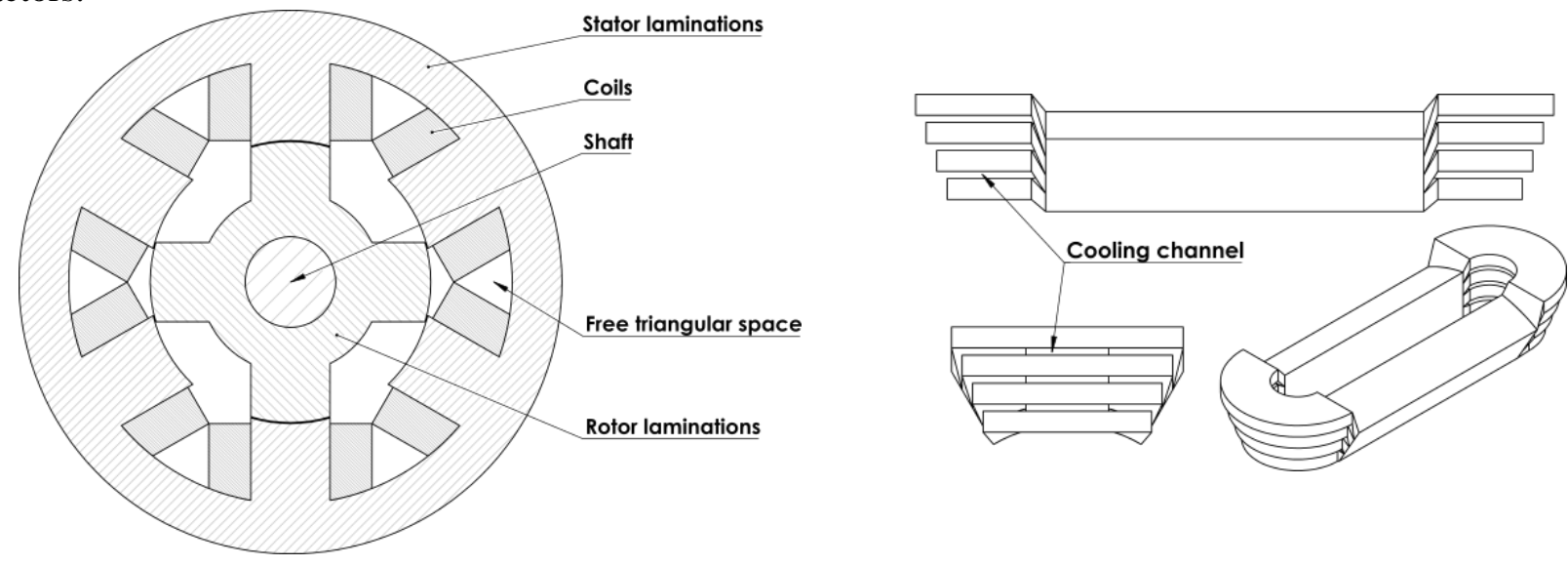

Fig. 1 Typical sectional view of 6/4-SRM (left) and stretched end winding cooling (right)

Four different cooling methods will be studied in this paper:

1) Water jacket cooling (WJC) as benchmarking and also as a combination with the other methods, because it is simple and robust and no coil space is occupied by this method. (see Fig. 3b.)

2) Direct coil cooling $\left(D C C_{c}\right)$ by inserting a stainless steel circular tube axially through the stator slot, between the two adjacent coils. This is a robust and simple design where the tube is pushed into the slot together with the coils. (see Fig. 3c.)

3) Direct coil cooling $\left(D C C_{t}\right)$ by pumping a fluid axially through the stator slot, between the two adjacent coils in the free space where no coil is present due to the use of preformed coils. (see Fig. 3d.)

4) Stretched end winding cooling (SEWC), where the wires at the end winding are pulled apart in several layers yielding a fluid flow in between (see Fig. 1 right). It is a more complex cooling method, but no coil space is occupied and the results are promising [12]. The practical and mechanical aspects of this cooling method are out scope for this paper.

\section{ADVANCED LUMPED PARAMETER MODEL}

In standard LP models, mostly one simple cooling method is implemented with which the thermal gradients are quite simple modeled in $1 \mathrm{D}$ or 2D. However high performing cooling methods in SR motors yield highly complex 3D thermal gradients which cannot be modeled by a simple lumped parameter model [16] [17]. Therefore, a more advanced LPM should be used which models the components with highly complex thermal gradients in more detail.

\subsection{General model overview}

In this paper the SRM will be modelled in Matlab with a LPM, based on conductive and convective connections between the coolants and nodes which represent the different components of the motor. In a cross section of the motor, more nodes are used for components where a high 2D thermal gradient occur compared to other components with lower thermal gradients. This is mainly necessary for the coil, since high thermal gradients are evident due to the low thermal conductivity and high heat generation. To assure a smooth transition from coil to the other components, the liners around the coil should also be meshed. In addition, the stator laminations can be meshed as well. To include the axial gradient in the motor, the motor is split into three main parts: the active part, the end winding part and the end plates which include a part of the housing, end flanges, bearings and a part of the shaft. When higher axial gradients occur as for example with stretched end winding cooling, the accuracy of the model can be improved with different axial slices of the active and end winding part. 
The different nodes of the components and slices of the motor should now be thermally connected to each other. To simulate the thermal behaviour when applying a certain load to the motor, the heat balance for every node is elaborated. Out of these energy balances, the Equations (1)-(3) can be constructed.

$$
\begin{gathered}
K * T=b, K=\left[\begin{array}{cccc}
K_{11} & K_{12} & \ldots & K_{1 n} \\
K_{21} & K_{22} & \ldots & K_{2 n} \\
\vdots & \vdots & \ddots & \vdots \\
K_{n 1} & K_{n 2} & \ldots & K_{n n}
\end{array}\right], T=\left[\begin{array}{c}
T_{1, t} \\
T_{2, t} \\
\vdots \\
T_{n, t}
\end{array}\right], b=\left[\begin{array}{c}
b_{1, t} \\
b_{2, t} \\
\vdots \\
b_{n, t}
\end{array}\right] \\
K_{i j}=K_{j i}=\frac{1}{R_{i j}}=\frac{1}{R_{j i}}, K_{i i}=-\left(\sum_{j \neq i}^{n} K_{i j}+\sum \frac{1}{R_{i, e x t}}+\frac{C_{i}}{\Delta t}\right)=-\left(\sum_{j \neq i}^{n} K_{j i}+\sum \frac{1}{R_{i, e x t}}+\frac{C_{i}}{\Delta t}\right) \\
b_{i, t}=-\left(\dot{Q}_{i}+\sum \frac{T_{i, e x t}}{R_{i, e x t}}+\frac{C_{i}}{\Delta t} T_{i, t-1}\right)
\end{gathered}
$$

In these equations, $\mathrm{K}$ is the conductance matrix, $\mathrm{T}$ is an array of the node temperatures, and $\mathrm{b}$ is dependent on the heat input, the heat transfer to external media and the temperature at the previous time iteration $t$. Further $i$ and $j$ represent nodes, $R_{i j}$ the thermal resistance between these nodes, $\dot{Q}_{i}$ the heat coming into node $i, R_{i, \text { ext }}$ the thermal resistance to the external temperature $T_{i, \text { ext }}$ of the medium, $C_{i}$ the heat capacity of node $i$ and $d t$ the time step.

Transient simulations with time step $\Delta t$ can also be performed with this model, where $t$ indicates the iteration in time. Out of this $b$ and $K$, the new temperatures at the end of moment $t$ can be calculated. However, the results of this transient modelling are out of scope for this paper since it is not necessary when comparing the cooling performance of the different advanced cooling approaches. Therefore, all capacities are set as zero in the following simulations to obtain the steady state results.

\subsection{Determination of thermal resistances}

Conductive heat transfer. To obtain the different conductive thermal resistances between the nodes, two approaches will be used. First as proposed by Wrobel et al. [13], the conduction in one direction in a cuboidal element can be modeled as a resistance network. This is a three resistance network for an element with internal heat generation (Fig. 2 left) and a two resistance network for conduction only (Fig. 2 right). This principle can be used to model the heat transfer in the axial direction in the motor, because this geometry and thermal gradient is relatively simple.
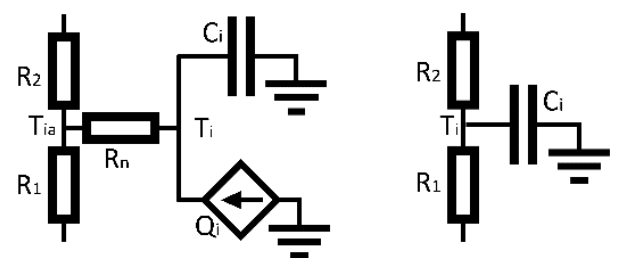

Fig. 2 Equivalent thermal network for cuboidal element with heat generation (left) and without (right) [13]

However, for most of the cooling methods, this method is difficult to use in the radial direction of the motor because of the complex geometry and thermal connections, together with the high gradients in radial direction. Therefore, the second more detailed method, i.e., a 2D radial FE simulation with the software package FEMM 4.2 has been used within this paper, such that the thermal resistances in radial direction can be obtained. Due to the symmetry of the motor and a distributed heat dissipation over the complete motor, only half of a stator tooth is modelled in the software package with adiabatic boundary conditions. Based on several inputs, the 
Matlab model is capable of automatically drawing, meshing and calculating the temperature distribution and heat flux in FEMM of half of the stator tooth for different configurations of an SRM. These inputs are:

- The geometry of the motor, cooling methods and lumped mesh locations;

- Heat generation in the different components and a first estimate of the distribution of the heat over the different cooling media;

- The cooling methods including configuration, average fluid temperatures and a first estimate of the convection coefficients;

- Thermal conduction coefficients of the different materials.

An example of such a FE simulation is shown in Fig 3.

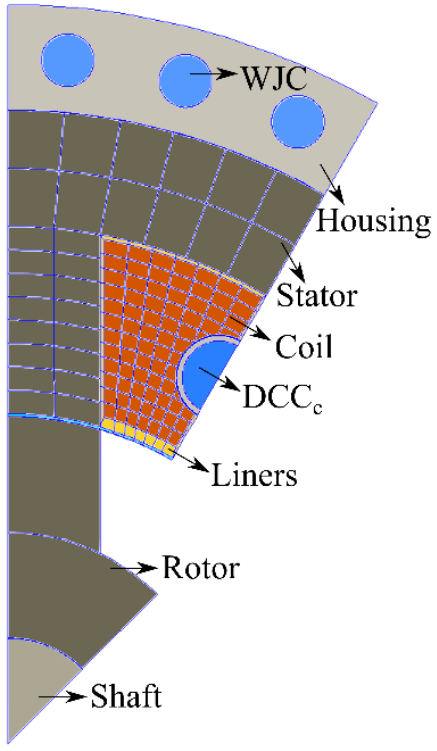

a. $W J C+D C C_{c}$

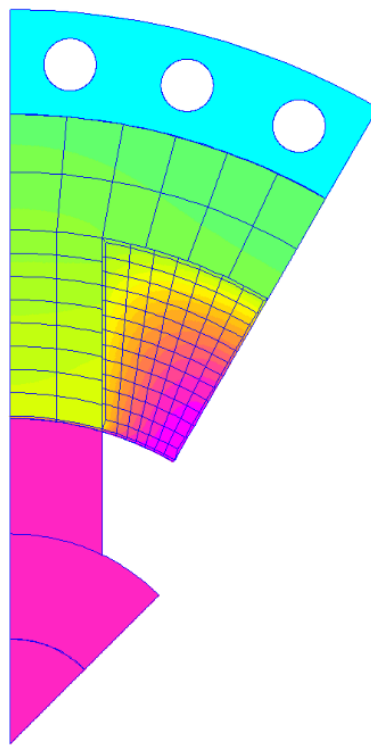

b. WJC

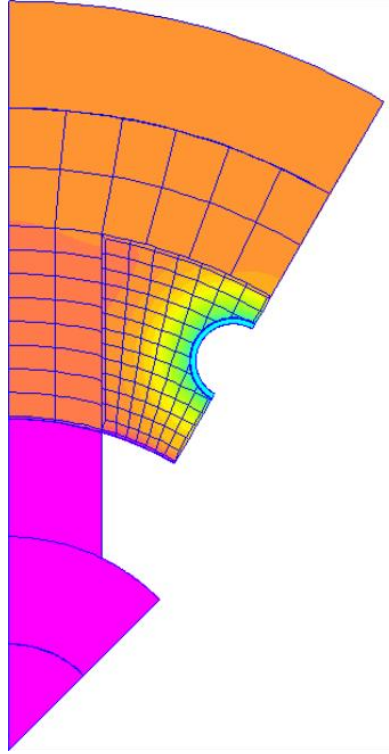

c. $D C C_{c}$

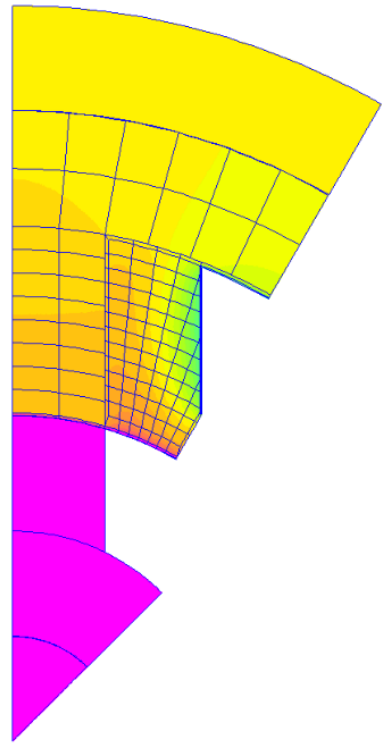

d. $D C C_{t}$

Fig. $3 a$. Half of stator tooth with $W J C$ and $D C C_{c} . b . c . d$. Output of FEMM for radial FE simulation.

Afterwards, the model is capable of extracting the necessary (lumped) data out of this first simulation. The data extracted from this model are: the cross sectional area of the different nodes $A_{i}$, the length of certain boundaries between nodes and external temperatures $L_{i}$, the average temperatures of the nodes $T_{i, a v g}$ and the heat going from one node to another $\dot{Q}_{i j}$. With this information, the thermal resistance between the nodes can be calculated by $R_{i j}=R_{j i}=\frac{\left|T_{i, a v g}-T_{j, a v g}\right|}{\dot{Q}_{i j}}$. Note, that after this FE simulation, the geometry and radial thermal resistances cannot be changed anymore. However, since the computational time of the FE simulation is short, adjustments of either the geometry or thermal resistances can easily be performed if necessary to analyse, e.g., different parameter ranges or the sensitivity of the solution to these parameters.

Out of the sectional areas and boundary lengths extracted from the FE simulation, the thermal resistances in axial direction can be constructed by using the method proposed in [13]. For each node with internal heat generation, an additional node is necessary which is then connected to the average node temperature with the negative resistance $R_{n}$. For components without internal heat generation, this additional node is not necessary and only the positive resistances $R_{1}$ and $R_{2}$ are used (simple 1D conduction). The two equivalent thermal networks are shown in Fig. 2 and can be calculated with $R_{1, i}=R_{2, i}=\frac{\Delta L}{2 * k_{i} * A_{i}}$ and $R_{n, i}=-\frac{\Delta L}{6 * k_{i} * A_{i}}$, where $\Delta L$ is the axial length of the slice and $k_{i}$ the thermal conductivity. The thermal resistance between the additional nodes of $i$ and $j$ can then be calculated with $R_{i a, j a}=R_{1, i a}+R_{2, j a}$. For the end windings, the same internal connections in radial direction are used as these obtained for the active part. It is assumed that the liners are not present in the end winding region because no short circuit can occur here. For the axial thermal resistances, 
the same method is used as for the active part. The thermal connections for the end plates are calculated out of the thermal resistances of a cylindrical unit as mentioned in [18] for the radial direction, and with the same axial thermal circuit as the other components.

Interface resistances. The different thermal interface resistances used in the model are based on findings and correlations from literature. For the heat transfer in the air gap the correlation of Romanazzi et al. is used [19] specifically obtained for a SRM. The correlation is based on the so-called modified Taylor number $T a_{m}$ calculated by $T a_{m}=\frac{\omega^{2} R_{m} \delta^{3}}{v^{2}} \frac{1}{F_{g}}$, where $\omega$ is the rotation speed, $\delta$ the gap width, $v$ the kinematic viscosity of the air, $R_{m}$ is the mean radius and $F_{g}$ is a geometrical factor, see [19] for more details. The Nusselt number of the heat transfer between the rotor and stator can be calculated by $N u=0.181 T a_{m}^{0.207}$, which is valid for $10^{2}<T a_{m}<3 * 10^{4}$.

At the interface of different components, a contact resistance exists due to imperfect touching of the two surfaces. These thermal interface resistances between the different components are studied by Staton et al. [20]. The thermal interface resistances are expressed as an equivalent air gap thickness between the components. They obtained an average value of $0.037 \mathrm{~mm}$ between the housing and laminations for different types and sizes of motors. In the model discussed in this paper, the same value is used for the thermal interface between shaft and rotor laminations. Staton et al. also studied the thermal interface resistance between shaft and flange caused by the bearings of the motor. Three types of bearings were experimentally measured and as an average value, an equivalent air gap thickness of $0.3 \mathrm{~mm}$ can be assumed [20].

Convective heat transfer. In the case of laminar flow, the convection coefficients $h_{\text {conv }}$ for the different cooling methods are based on the correlations for laminar flow in ducts and triangular ducts described by Shah and London [21]. Depending on the configuration of the cooling method, the correlations for both hydraulically developed and simultaneously developing flow are implemented as extensively elaborated in the mentioned work. When the flow in the ducts becomes turbulent, the correlation of Gnielinski [22] is used to calculate the forced convection coefficients. In the region of transitional flow a linear interpolation between the Nusselt numbers at $R e=2300$ and $R e=4000$ is used to determine the Nusselt number in this region, a detailed description of the different Nusselt numbers can be found in [22] and [21]. The thermal resistance resulting from this cooling methods can then be determined as $R_{i, \text { ext }}=1 /\left(h_{\text {conv }} L_{i} \Delta L\right)$.

\subsection{Heat losses}

The following heat dissipations occur in an SRM, they are put in the order of importance: $\dot{Q}_{\text {copper }}, \dot{Q}_{\text {stator }}$, $\dot{Q}_{\text {rotor }}, \dot{Q}_{\text {windage }}$ and $\dot{Q}_{d c c}$ tube . All of these heat losses will be used as an input to the model, except the windage losses in the air gap. These losses are computed by the correlation of Kiyota et al. [23]: $\dot{Q}=(K-1) \pi C_{d} \rho R^{4} \omega^{3} L$, with $\rho$ the air density, $R$ the rotor outer radius, $L$ the rotor axial length, $K$ the salient pole coefficient and $C_{d}$ the drag coefficient. These last two coefficients can be found in the work of Kiyota et al [23]. To make a comparison between the performance of the cooling methods, two additional corrections are taken into account:

- Copper losses are recalculated with the available area for the coil, fill factor and average temperature,

- Losses in the $\mathrm{DCC}_{\mathrm{c}}$ tube are taken into account as $0,33 \%$ of the total power for a stainless steel tube [6].

\section{COMPARISON OF COOLING METHODS}

With the model implemented as described above, the performance of the different cooling methods can be compared. Therefore, several parameters are fixed to reduce the amount of variables which do not contribute to the comparison. The motor speed and power are fixed during all the simulations. The mesh size in FEMM is the same for every geometry and a fixed lumped meshing is used for the stator ( 28 nodes) and coil (7x12 nodes). Axially, the active part has 8 slices and the end winding part has 5 slices. The coil fill factor is $50 \%$ [14] in every case, except for $D C C_{t}$. For every cooling method, the flow rate is fixed at $10 \mathrm{l} / \mathrm{min}$. For the cooling methods where the fluid can come into direct contact with the motor, an Automatic Transmission Fluid 
(ATF) is used. For the other applications a 50/50\% mixture of Water-Glycol (WG) is used. Most of the model inputs are shown in Table 1. The hydraulic layout of the different methods is as follows:

- $\quad W J C$ consists of 36 circular axial channels, of which 3 are in series and 12 are in parallel,

- $D C C_{c}$ consists of 6 parallel, circular steel tubes running axially through the adjacent coils,

- $D C C_{t}$ consists of 6 triangular direct cooling channels between the adjacent coils, per two in series,

- $\quad S E W C$ consists of 2 parallel loops, each running at one side of the motor where the fluid passes the stretched end windings in series (6 times).

Table 1 Motor and cooling method inputs for model (unless otherwise specified, units are in $\mathrm{mm}$ ).

\begin{tabular}{|c|c|c|c|c|c|}
\hline General motor properties & & Cooling properties & & $\underline{\text { SEWC properties }}$ & \\
\hline$\overline{\text { Stator poles }(-)}$ & 6 & $\overline{\text { WJC properties }}$ & & $\overline{\text { Amount of layers }}(-)$ & 3 \\
\hline Rotor poles (-) & 4 & Channel diameter & 4 & Cooling channels height & 2 \\
\hline Number of phases (-) & 3 & Inlet temperature $\left({ }^{\circ} \mathrm{C}\right)$ & 40 & Epoxy layer thickness & 0,2 \\
\hline Nominal power (kW) & 15 & Fluid (-) & WG & Inlet temperature $\left({ }^{\circ} \mathrm{C}\right)$ & 40 \\
\hline Nominal speed (rpm) & 15000 & & & Fluid (-) & ATF \\
\hline Stack length & 80 & $\underline{D C} C_{\underline{c}}$ properties & & Mean end winding length & 62 \\
\hline Air gap thickness & 0,25 & Tube diameter & 8 & & \\
\hline Outer diameter stator & 120 & Tube wall thickness & 0,5 & $\underline{\text { Heat inputs }}$ & \\
\hline Stator tooth width & 17,5 & Radius of tube location & 42 & $\overline{\text { Stator losses }}(\mathrm{W})$ & 78,4 \\
\hline Stator yoke thickness & 11 & Coil-tube liner & 0,08 & Rotor losses (W) & 35,6 \\
\hline Rotor outer diameter & 62 & Inlet temperature $\left({ }^{\circ} \mathrm{C}\right)$ & 40 & Heat losses in $D C C_{c}$ tube (W) & 50 \\
\hline Rotor tooth width & 17,5 & Fluid (-) & WG & & \\
\hline Rotor yoke thickness & 11 & & & Components properties & $\boldsymbol{k}_{\boldsymbol{t h}}(W / m K)$ \\
\hline Shaft diameter & 20 & $\underline{D C C_{t} \text { properties }}$ & & Housing (Aluminum) & 200 \\
\hline Mean end winding length & 42 & Channel height & 12,9 & Stator\&rotor radial [13] & 22,2 \\
\hline End space width & 40 & Channel width & 14,3 & Stator\&rotor axial [13] & 4,9 \\
\hline End winding over length & 11 & Stator-channel liner & 0,33 & Shaft (Carbon steel) & 43 \\
\hline End flange thickness & 5 & Epoxy layer thickness & 0,1 & Liners (Nomex) & 0,25 \\
\hline Bearing outer diameter & 42 & Inlet temperature $\left({ }^{\circ} \mathrm{C}\right)$ & 40 & Coil radial [15] & 1,03 \\
\hline Bearing width & 20 & Fluid (-) & ATF & Coil axial [15] & 250 \\
\hline Coil-air gap liner & 1 & Fill factor $(\%)[15]$ & 65 & Epoxy [15] & 0,21 \\
\hline Coil-stator liner & 0,35 & kcoil,radial (W/mK) [15] & 1,34 & Tube (Stainless steel) & 16 \\
\hline Coil-coil liner & 0,25 & & & Flange (Aluminum) & 200 \\
\hline
\end{tabular}

An example of the temperature-distribution output of the model is shown in Fig. 4 and some other outputs of the model are shown in Table 2, which are relevant for making a comparison between the different methods and combinations. In the calculation of the pumping power, only the pressure drop due to the flow in the cooling channel is used (so inlet and outlet effects are not taken into account).
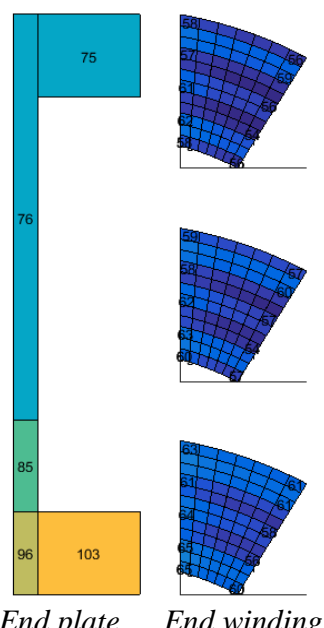

End plate

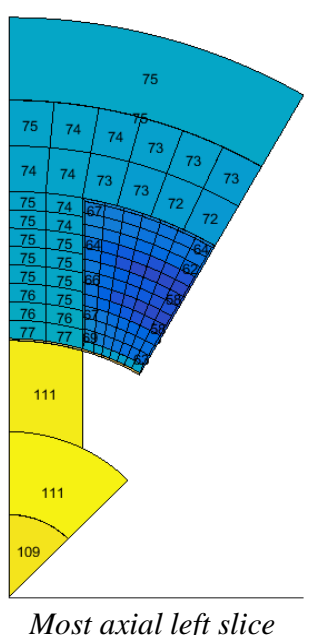

End winding Most axial left slice

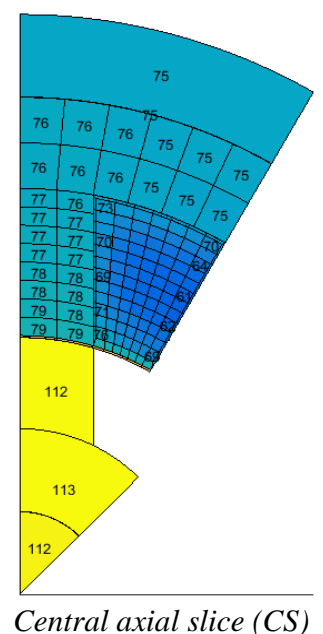

Central axial slice $(C S)$
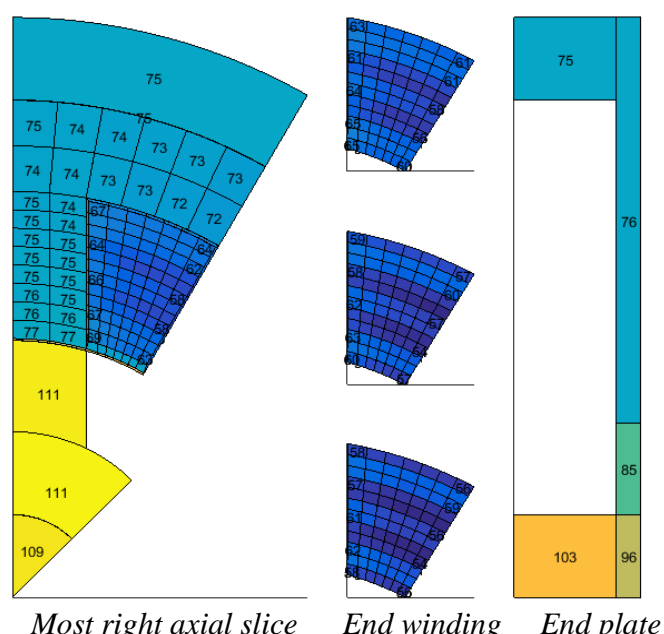

Fig. 4 Temperature distribution output for the SEWC case (slice order from left to right and top to bottom). 
Table 2 Results of the cooling methods and combinations, applied on the SRM. At the central slice $=$ CS

\begin{tabular}{|c|c|c|c|c|c|c|c|}
\hline Cooling method & $W J C$ & $D C C C$ & $D C C t$ & $S E W C$ & $W J C+D C C c$ & $W J C+D C C t$ & $W J C+S E W C$ \\
\hline$\dot{Q}$ to WJC (\%) & 100 & 0 & 0 & 0 & 71 & 71 & 38 \\
\hline$\dot{Q}$ to $\mathrm{DCC}(\%)$ & 0 & 100 & 100 & 0 & 29 & 29 & 0 \\
\hline$\dot{Q}$ to SEWC (\%) & 0 & 0 & 0 & 100 & 0 & 0 & 62 \\
\hline$T_{\text {avg }}$ coil $\left({ }^{\circ} \mathrm{C}\right)$ & 110,7 & 289,9 & 163,9 & 60,0 & 93,0 & 86,7 & 52,7 \\
\hline $\boldsymbol{T}_{\text {avg }}$ stator $\left({ }^{\circ} \mathrm{C}\right)$ & 74,5 & 320,0 & 168,7 & 75,2 & 69,0 & 65,3 & 53,1 \\
\hline $\boldsymbol{T}_{\text {avg }} \operatorname{rotor}\left({ }^{\circ} \mathrm{C}\right)$ & 128,5 & 348,8 & 208,3 & 111,5 & 119,8 & 115,2 & 94,6 \\
\hline $\boldsymbol{T}_{\max } \operatorname{coil}\left({ }^{\circ} \mathrm{C}\right)$ & 131,0 & 324,4 & 179,0 & 76,3 & 111,3 & 100,1 & 62,4 \\
\hline $\boldsymbol{T}_{\max }\left({ }^{\circ} \mathrm{C}\right)$ & 138,7 & 349,8 & 209,3 & 112,8 & 126,5 & 119,6 & 95,9 \\
\hline Location $T_{\max }$ & Airgap CS & Rotor CS & Rotor CS & Rotor CS & Airgap CS & Airgap CS & Rotor CS \\
\hline $\boldsymbol{h}_{W J \boldsymbol{C}}\left(\mathrm{W} / \mathrm{m}^{2} \mathrm{~K}\right)$ & 1070 & 0 & 0 & 0 & 1067 & 1064 & 1061 \\
\hline $\boldsymbol{h}_{D C C}\left(\mathrm{~W} / \mathrm{m}^{2} \mathrm{~K}\right)$ & 0 & 2582 & 288 & 0 & 2479 & 257 & 0 \\
\hline $\boldsymbol{h}_{\text {SEWC }}\left(\mathrm{W} / \mathrm{m}^{2} \mathrm{~K}\right)$ & 0 & 0 & 0 & 1550 & 0 & 0 & 1540 \\
\hline Pump power $(\mathrm{W})$ & 0,152 & 0,015 & 0,373 & 2,302 & 0,166 & 0,530 & 2,465 \\
\hline Coil area $\left(\mathrm{mm}^{2}\right)$ & 193 & 169 & 148 & 193 & 169 & 148 & 193 \\
\hline Copper losses (W) & 242 & 414 & 279 & 242 & 261 & 226 & 236 \\
\hline Efficiency $(\%)$ & 97,3 & 95,9 & 97,1 & 97,3 & 96,8 & 97,4 & 97,3 \\
\hline
\end{tabular}

From a thermal point of view and when applying the different cooling methods separately from each other, the SEWC performs the best with $T_{\max }=113^{\circ} \mathrm{C}$ (due to the high axial conductivity of the coil and large surface area in contact with the fluid), followed by WJC with $T_{\max }=139^{\circ} \mathrm{C}$ (due to the large surface area in contact with fluid). The two DCC methods (with $T_{\max }=350^{\circ} \mathrm{C}$ for $\mathrm{DCC}_{\mathrm{c}}$ and $T_{\max }=209^{\circ} \mathrm{C}$ for $\mathrm{DCC}_{\mathrm{t}}$ ) perform worse than WJC, because all of the heat of the stator and rotor should be transferred through the coil before it can reach the coolant and the heat transfer area is also rather small. This problem can be solved by combining these methods with WJC, by which the performance becomes much better compared to WJC alone. Combining SEWC with WJC results in extremely low temperatures $\left(T_{\max }=96^{\circ} \mathrm{C}\right)$ since the two methods complement each other (WJC for stator and rotor, SEWC for coil). The results of the comparison between the methods as shown in this paper, were not possible with the information from previous studies. Despite the fact that $\mathrm{DCC}_{\mathrm{t}}$ results in the smallest area available for copper, it still performs good on efficiency and copper losses and even the best in combination with WJC $(\eta=97,4 \%)$. This is due to the assumption of a higher fill factor resulting in a higher thermal conductivity of the coil (so lower temperatures) and in lower copper losses (more copper and lower temperature), which compensates the lower area. DCCc performs the worst on efficiency due to the assumption of the $0,33 \%$ losses in the steel tube by the induced eddy currents. To avoid this, a non-metallic material could be used but this is detrimental for the heat transfer to the fluid. From the point of view of efficiency, SEWC ( $\eta=97,3 \%)$ performs as good as WJC and DCC $_{t}$. So despite the extra wire length which is necessary to implement the cooling method, the copper losses are still lower due to the lower coil temperature. A drawback of SEWC is the higher pressure drop resulting in a higher pumping power.

\section{CONCLUSIONS}

With the developed lumped parameter model in this paper, a comparison was made between four cooling methods and the combination of these methods applied on a SRM. Direct coil cooling as the only cooling method turns out to be worse than water jacket cooling and stretched end winding cooling. In combination with water jacket, the cooling methods perform much better than without, but the stretched end winding cooling remains the best performing method. In any case, the results of these simulations will only give an indication of the performance of the cooling methods compared to each other. This is because the different variables (such as losses, interfaces and material properties) of the model are based on findings in literature and the uncertainty on these variables is quite large. To overcome this, the different variables of this model should be validated based on experimental results of the cooling methods applied to a real SRM. Therefore different setups are being built in the framework of the Hipercool project to validate and improve the developed model in the future. With the validated model, it should be possible to make a final choice between the different methods while taking other parameters into account such as cost, practical feasibility and extra losses in the motor. 


\section{ACKNOWLEDGMENT}

This research was supported by Flanders Make, the strategic research centre for the manufacturing industry, and the HERMESFONDS in the framework of the Hipercool project (HBC.2016.0463).

\section{NOMENCLATURE}

\begin{tabular}{lll|lll}
$b$ & Constant & $(-)$ & $K$ & Thermal conductance & $(W / K)$ \\
$C_{d}$ & Drag coefficient & $(-)$ & $R$ & Thermal resistance & $(K / W)$ \\
$c_{s p}$ & Salient pole coefficient & $(-)$ & $T a_{m}$ & Modified Taylor number & $(-)$ \\
$F_{g}$ & Geometrical factor & $(-)$ & & &
\end{tabular}

\section{REFERENCES}

[1] Haghbin, S., Rabiei, A. and Grunditz, E., "Switched Reluctance Motor in Electric or Hybrid Vehicle Applications: A Status Review," Proc. of 8th Industrial Electronics and Applications Conf., ICIEA13, pp. 1017-1021, (2013).

[2] Popescu, M., Staton, D. A., Boglietti, A., Cavagnino, A., Member, S., Hawkins, D., and Goss, J., "Modern Heat Extraction Systems for Power Traction Machines - A Review," IEEE Transactions on Industry Applications, 52(3), pp. 2167-2175, (2016).

[3] Tighe, C., Gerada, C. and Pickering, S., "Assessment of cooling methods for increased power density in electrical machines," Proc. of 22th Int. Conf. on Electrical Machines, ICEM16, pp. 4-7, (2016).

[4] Schiefer, M. and Doppelbauer, M., "Indirect Slot Cooling for High-Power-Density Machines with Concentrated Winding," IEEE Electric Machines \& Drives Conf., IEMDC15, pp. 1820-1825, (2015).

[5] Semidey, S. A. and Mayor, J. R., "Experimentation of an Electric Machine Technology Demonstrator Incorporating Direct Winding Heat Exchangers," IEEE Transactions on Industrial Electronics, 61(10), pp. 5771-5778, (2014).

[6] Fairall, E. et al., "Maximizing Thermal Effectiveness and Minimizing Parasitic Loss in a Liquid Cooled Switched Reluctance Machine," Proc. IEEE Transportation Electrification Conf. and Expo, ITEC16, pp. 1-7, (2016).

[7] Rhebergen, C., Bilgin, B., Emadi, A., Rowan, E., Lo, J., Ontario, H., and Lo, J., "Enhancement of Electric Motor Thermal Management through Axial Cooling Methods: A Materials Approach," Proc. IEEE Energy Conversion Congress and Exposition, ECCE15, pp. 5682-5688, (2015).

[8] Márquez-Fernández, F. J., Potgieter, J. H. J., Fraser, A. G., and Mcculloch, M. D., "Thermal management in a high speed switched reluctance machine for traction applications," Proc. 8th IET Int. Conf. on Power Electronics, Machines and Drives, PEMD16, pp. 1-6, (2016).

[9] Liu, Z., Winter, T. and Schier, M., "Comparison of Thermal Performance between Direct Coil Cooling and Water Jacket Cooling for Electric Traction Motor based on Lumped Parameter Thermal Network and Experimentation”, Proc. Int. Electric Vehicle Symposium and Exhibition, EVS28, (2015).

[10] Davin, T. et al., "Experimental study of oil cooling systems for electric motors," In Applied Thermal Engineering, 75, pp. 1-13, (2015).

[11] Hsu, J.S., "Report on Toyota Prius Motor Thermal Management," ORNL/TM-2005/33, (2005).

[12] Brown, G.V., Jansen, R.H. and Trudell, J.J, "High Specific Power Motors in LN2 and LH2," Cryogenic Engineering Conf. and International Cryogenic Materials Conf., CEC-ICMC7, (2007).

[13] Wrobel, R. and Mellor P. H., "A General Cuboidal Element for Three-Dimensional Thermal Modelling," IEEE Transactions on Magnetics, 46 (8), pp. 3197-3200, (2010).

[14] Laudensack, C., Yu, Q. and Gerling, D., "Investigation of Different Parameters on the Performance of Switched Reluctance Machines," Proc. of 19th Int. Conf. on Electrical Machines, ICEM10, pp.1-6, (2010).

[15] Siesing, L., Reinap, A. and Andersson, M., "Thermal properties on high fill factor electrical windings: Infiltrated vs non infiltrated," Proc. Int. Conf. on Electrical Machines, ICEM14, pp. 2218-2223, (2014).

[16] Shoujun, S., Weiguo, L. and Schaefer, U., "Thermal analysis of a 30kW Switched Reluctance Starter/Generator system used in aircraft," Proc. of Int. Conf. on Power Engineering, Energy and Electrical Drives, POWERENG2009, pp. 331-336, (2009).

[17] Rouhani, H., Faiz, J., Lucas,C., "Lumped thermal model for switched reluctance motor applied to mechanical design optimization," Mathematical and Computer Modelling, 45(5-6), pp. 625-638 (2007).

[18] Qi, F., Stippich, A., Guettler, M., Neubert, M., and De Doncker, R. W., "Methodical considerations for setting up space-resolved lumpedparameter thermal models for electrical machines," Proc. 17th Int. Conf. on Electrical Machines and Systems, ICEMS14, pp. 651-657, (2014).

[19] Romanazzi, P. and Howey, D. A., "Air-gap convection in a switched reluctance machine," Proc. 10th Int. Conf. on Ecological Vehicles and Renewable Energies, EVER, pp. 1-7 (2015).

[20] Staton, D., Boglietti, A. and Cavagnino, A., "Solving the More Difficult Aspects of Electric Motor Thermal Analysis in Small and Medium Size Industrial Induction Motors," IEEE Transactions on Energy Conversion, 20(3), pp. 620-628, (2005).

[21] Shah, R.K. and London, A.L., Laminar Flow Forced Convection in Ducts, New York: ACADEMIC PRESS, pp. 78-246, (1978).

[22] Gnielinski, V., "On heat transfer in tubes," Int. Journal of Heat and Mass Transfer, 63, pp. 134-140. (2013)

[23] Kiyota, K., Kakishima, T., and Chiba, A.., "Estimation and Comparison of the Windage Loss of a $60 \mathrm{~kW}$ Switched Reluctance Motor for Hybrid Electric Vehicles," Proc. Int. Power Electronics Conf., IPEC2014, pp. 3513-3518, (2014). 